УДК 618.2-055.28

\title{
ОСОБЕННОСТИ ТЕЧЕНИЯ БЕРЕМЕННОСТИ И РОДОВ У МНОГОРОЖАВШИХ ЖЕНЩИН
}

\author{
Киселевич Михаил Федорович \\ к.м.н., доцент, \\ доцент кафедры акушерства и гинекологии медицинского института \\ Киселевич Марианна Михайловна \\ к.м.н., доцент, \\ доцент кафедры пропедевтики внутренних болезней \\ и клинических информационных технологий \\ Улезько Анастасия Александровна \\ Бабалиева Гамер Ниязовна \\ Белгородский государственный национально \\ исследовательский университет НИУ «БелГУ»
}

Аннотация: Проведен анализ течения беременности и родов у 1752 многорожавших женщин. Частота родов у многорожавших составила $11,6 \%$ случаев. Течение беременности и родов характеризовалось высоким процентом осложнений (72,2\% и 78,0\% соответственно).

Ключевые слова: многорожавшая, беременность, течение беременности и родов.

\section{FEATURES OF THE COURSE OF PREGNANCY AND DELIVERY IN PLURIPARA WOMEN}

\author{
Kiselevich Michail Fedorovich \\ Kiselevich Marianna Michailovna \\ Ulesko Anastasia Aleksandrovna \\ Babalieva Hamer Niysovna
}

\begin{abstract}
The analysis of the course of pregnancy and delivery in 1752 pluripara women was carried out. The birth rate in pluripara women was $11.6 \%$ of cases. The course of pregnancy and delivery was characterized by a high percentage of complications (72.2\% and $78.0 \%)$.
\end{abstract}

Key words: pluripara woman, pregnancy, course of pregnancy and delivery. 
Актуальность проблемы. В акушерстве особое значение уделяется многорожавшим женщинам, так как они относятся высокой степени риска по материнским и перинатальным осложнениям [1, с.30, 2, с.18, 5, с.168]. У них чаще наблюдаются гинекологические и экстрагенитальные заболевания, а также укорочение интервалов между родами. Кроме того, они относятся к старшей возрастной группе [3, с.16]. Осложнения во время беременности у многорожавших чаще возникают чем при нормальной беременности. В родах ввиду дистрофических процессов в матке происходит нарушение сократительной деятельности, которая является причиной кровотечений и субинволюции матки $[5$, с.175, 7, с.353]. В группе многорожавших также отмечаются высокие показатели материнской и перинатальной смертности [6, c.168].

Частота родов у многорожавших женщин по данным различных авторов составляет от $2,8-35 \%$ случаев [1, с.32, 4 , с.16, 7, с.353].

Цель исследования. Изучить особенности течения беременности и родов у многорожавших женщин.

Материал и методы. Проведен анализ историй родов у многорожавших женщин за 2016 - 2018 гг. в Перинатальном центре Белгородской областной клинической больницы святителя Иоасафа.

Результаты и обсуждение. Всего за этот период было проведено 15128 родов, из них у многорожавших женщин, имевших 3 и более родов, было 1752 случаев, что составляет $11,6 \%$.

Частота родов по годам изменялась и почти одинаковое число родов отмечалось в 2016 и 2018 годах (с 5488 до 5122 случаев), а в 2017 незначительное снижение родов (4518 случаев). За этот период число родов у многорожавших так же имело тенденцию к снижению (с 665 до 503 случаев).

В исследованиях среди обследуемых преобладали жительницы городской местности 1220(69,6\%), а сельской - 532(30,4\%) женщин.

Большой интерес представляло изучение возраста среди многорожавших. Возраст колебался от 20 до 40 лет и старше. В возрасте 20-30 лет было $506(28,5 \%)$ женщин, в возрасте 31-35 - 747(42,6\%), в возрасте 36-40 $438(25,0 \%)$ и свыше 40 лет - 61(3,5\%). Наибольшее число женщин было в возрасте от 31 до 35 лет (42,6\% случаев), а затем по годам их численность снижалась (с 28,5\% до 3,5\% случаев).

Все обследуемые женщины были повторнородящими. Так, 3 роды были у 1237(70,6\%) женщин, 4 роды у $318(18,1 \%), 5$ роды у 131(7,5\%), 6 роды у 
53(3,1\%), 7 роды у $11(0,6 \%), 8$ роды у $2(0,1 \%)$. Среди обследуемых женщин наиболее часто встречались трети роды $(70,6 \%)$, затем четвертые $(18,1 \%)$ и пятые (7,5\%), а остальные встречались реже. Беременность у 21 женщины наступила после проведения ЭКО.

Экстрагенитальные заболевания встречались довольно часто у 1127(65,5\%) беременных: ожирение (213), хронический пиелонефрит (189), НЦД по гипертоническому типу (174), миопия (132), варикозная болезнь (163), анемия (167) и гепатит (89). Гинекологические заболевания были у 495 (28,2\%) женщин. Искусственные аборты имели 225(45,5\%), самопроизвольные выкидыши - у 57(20,2\%), кольпиты - у 105(21,2\%), хронический аднексит - у $23(4,6 \%)$ женщин, эрозию шейки матки - у 80(16,1\%), миома матки - у 3 $(0,2 \%)$, киста яичника - 2(0,1\%). Таким образом, у обследованных женщин отмечался высокий процент экстрагенитальных $(66,5 \%)$ и гинекологических $(28,2 \%)$ заболеваний. Все беременные находились под наблюдением в группе высокого «риска».

Беременность протекала с различными акушерскими и перинатальными осложнениями. Наиболее часто встречалась ХФПН (хроническая фетоплацентарная недостаточность) у 502(28,7\%) и причиной ее была функциональная недостаточность плаценты, обусловленная гинекологическими и экстрагенитальными заболеваниями в анамнезе. Анемия 1-11 степени наблюдалась у 223(41,3\%) на ранних сроках в 10-14 недель и в 28-30 недель и всем им было проведено амбулаторное лечение. Ранний токсикоз легкой и средней степени тяжести наблюдался у 95(5,4\%) женщин в первом триместре. Беременным с средней степенью токсикоза проводилось стационарное лечение. Гестозы возникали на поздних сроках в 34-35 недель у 196 (11,2\%), причем в легкой степени у 100 беременных и в средней степени - у 96. Всем больным было проведено лечение в акушерском стационере. Кроме того, у беременных наблюдались и другие осложнения: у 104 (5,9\%) было многоводие, у 78(4,4\%) гестационный пиелонефрит, у 67(3,8\%) - маловодие. Таким образом, во время беременности наблюдался высокий процент осложнений у 1265(72,2\%) женщин. Без осложнений беременность протекала у 487(27,8\%) женщин. Заблаговременная дородовая госпитализация беременных в акушерский стационар была проведена у $97 \%$ случаях.

Особенно важным в исследовании было изучение течения родов. Своевременные роды через естественные родовые пути произошли у 1398(79,8\%) женщин. Преждевременные роды произошли через естественные 
пути и наблюдались у 215 (12,3\%) женщин на сроках 30-34 недель. Оперативные роды проводились у 139(7,9\%) женщин путем операции кесарево сечение. Экстренное кесарево сечение проводилось чаще у 128(92,0\%) женщин по поводу преждевременной отслойки нормально расположенной плаценты (33), острой гипоксии плода в родах (71), аномалий родовых сил (24). Плановое кесарево сечение проводилось у $11(8,0 \%)$ женщин ввиду повторного рубца на матке (7), тяжелого гестоза (3) и поперечного положения плода (1).

Самостоятельные роды протекали с высоким процентом осложнений у 1368(78,0\%) женщин. Самым грозным осложнением в родах и после родов было кровотечение, которое наблюдалось в 437(24,9\%) случаях. Причиной кровотечения у 180(41,2\%) женщин была патология прикрепления плаценты (плотное прикрепление плаценты у 109 и приращение плаценты у 23). У 172 (39,4\%) женщин причиной была гипотония матки (169) и задержка в матке частей последа (51). Кроме того, причиной кровотечения у 85 (19,5\%) были травмы родовых путей (разрывы шейки матки у 56, разрывы влагалища у 20 и промежности у 9).

У 395(22,5\%) женщин была ХВГП (хроническая внутриутробная гипоксия плода). Это было самое частое осложнение, наблюдавшееся во время беременности, а затем продолжалось в родах. Причиной ее были; хроническая плацентарная недостаточность (182), экстрагенитальные заболевания (сердечно-сосудистой системы 83, дыхательной системы 35, эндокринной системы 15,заболевания почек 43) и поздние гестозы (37). Патология излития околоплодных вод зарегистрирована в 260 (14,8\%) случаях, причем преждевременное излитие вод - у 197, а раннее - у 63 женщин. Малые акушерские операции проводились у 231 (13,2\%) женщин, из них ручное отделение плаценты (157) и ручная ревизия матки (74).

Реже встречались такие осложнения как аномалии родовых сил (18), длительный безводный период (15) и затяжные роды (12). Таким образом, наиболее частыми осложнениями в родах были кровотечение $(24,9 \%)$, ХВГП $(22,5 \%)$, преждевременное излитие вод $(14,8 \%)$ и ручное вхождение в матку $(13,2 \%)$, а другие осложнения встречались реже.

В родах всего родилось 1752 детей, из них - 1750 (99,9\%) живых и в 2 $(0,1 \%)$ случаях мертворожденные (антенатальная смерть плода) на фоне преждевременной отслойки нормально расположенной плаценты.

По полу родилось 1087(62,0\%) мальчиков и 665 (38,0\%) девочек. При рождении масса тела детей до 2000 г составила - 82 (4,7\%), от 2001-2500 г - 133 
(7,6\%), от 2501-3000 г - 305 (17,4\%), от $3001-3500$ г -546 (31,7\%), от 3501- 4000 г - $414(23,6 \%)$ и от 4001-5000 г - $124(170 \%)$ и свыше 5000,0 - 9(0,5\%) детей. Таким образом, при рождении количество мальчиков преобладало над количеством девочек (62,0\% и $38,0 \%$ соответственно), а их масса тела в основном была от 3001-3500 граммов (31,7\%).

На первой минуте по шкале Апгар имели оценку при рождении 0 баллов имели $2(0,1 \%)$ детей, от $1-2$ баллов - $9(0,5 \%)$, от 3-4 баллов - $27(1,5 \%)$, от 5-6 баллов - $186(10,6 \%)$, от 7-8 баллов - $1212(69,8 \%)$ и 8-10 баллов - 216(12,3\%) детей. В $12,7 \%$ случаев новорожденным, родившимся в асфиксии, были проведены реанимационные мероприятия.

Послеродовой период у женщин протекал удовлетворительно и только у 21(1,2\%) осложнился эндометритом (3) и субинволюцией матки (18).

В заключение следует отметить, что частота многорожавших женщин по годам снижалась и составила $11,6 \%$ случаев. Течение беременности и родов у них характеризовалось высоким процентом осложнений (72,2\% и $78,0 \%$ соответственно).

\section{Список литературы}

1. Аджиева Д.А., Нурмагомедова С.С. «Особенности течения беременности, родов и послеродового периода у многорожавших». //Медицина: актуальные вопросы и тенденции развития. Материалы II Международной научно-практической конференции. Сборник статей. Краснодар, 2013. - С. 32

2. Аджиева Д.А. Прегравидарная подготовка многорожавших женщин. Автореферат диссертации на соискание ученой степени канд. мед. наук. Махачкала. - 2014. - 23 с.

3. Бегова С.В. Исходы родов у многорожавших женщин в зависимости от национальной принадлежности. Успехи современного естествознания. -2007. №9.- С. $-41-42$.

4. Бенюк В.А., Майданник И.В., Саллами Мохамед Амин. Респективный анализ течения беременности и родов у многорожавших женщин. Зб1рник наукових праць асоц1ац11 акушер1в-гинеколог1в Укра1ни. г. Киев. Випуск 1/2 (33/34), 2014.- C. 16-17.

5. Мусангузова М.Ю. Профилактика и лечение аномалий родовой деятельности у многорожавших женщин: Дисс. ... канд. мед. наук. -Махачкала. $-2007 .-174 \mathrm{c}$. 
6. Муцаева З.Д. Здоровье беременных в регионе с высокой рождаемостью // Мать и дитя: Матер.VIII Рос. Форума. - М., 2006.- С. 168.

7. Callaghan W.M., Kuklina E.V., Berg C.J. Trends in postpartum hemorrhage: United States, 1994-2006 // Am.J. Obstet. Gynecol. - 2010. - Vol. 202. № 4. - P. 353 .

(C) Киселевич М.Ф., 2021 